\title{
Optimization of Different Temperature Annealed Nanostructured CdSe Thin Film for Photodetector Applications
}

\section{Alagarasan Devarajan}

Indian Institute of Science

S. Varadharajaperumal

Indian Institute of Science

K. Deva Arun Kumar

College of Engineering

R. Naik

Institute of Chemical Technology-Indian Oil Odisha Campus

\section{A. Arunkumar}

Arul Anandar College

R. Ganesan ( $\nabla$ gans@iisc.ac.in )

Indian Institute of Science

Ehab El Sayed Massoud

King Khalid University

\section{Research Article}

Keywords: photodetector, CdSe, band gap, refractive index

Posted Date: August 19th, 2021

DOl: https://doi.org/10.21203/rs.3.rs-807640/v1

License: (c) (i) This work is licensed under a Creative Commons Attribution 4.0 International License. Read Full License 


\title{
Optimization of different temperature annealed nanostructured CdSe thin film
} for photodetector applications

\author{
Devarajan Alagarasan $^{\mathrm{a}^{*}}, \mathrm{~S}$. Varadharajaperumal ${ }^{\mathrm{b}}, \mathrm{K}$. Deva Arun Kumar ${ }^{\mathrm{c}}$, R. Naik ${ }^{\mathrm{d}}, \mathrm{A}$. \\ Arunkumare, R. Ganesan $^{\mathrm{a} *}$, Ehab El Sayed Massoud ${ }^{\mathrm{f}, \mathrm{g}, \mathrm{h}}$ \\ ${ }^{\text {a }}$ Department of Physics, Indian Institute of Science, Bangalore, 560012, India \\ ${ }^{\mathrm{b}}$ Centre for Nano Science and Engineering, Indian Institute of Science, Bangalore, 560012, \\ India \\ ${ }^{\mathrm{c}}$ Shibaura Institute of Technology, College of Engineering, 337-8570, Saitama, Japan \\ ${ }^{\mathrm{d}}$ Department of Engineering and Materials Physics, Institute of Chemical Technology- \\ Indian Oil Odisha Campus, Bhubaneswar, 751013, India \\ ${ }^{\mathrm{e}}$ PG\& Research Department of Physics, Arul Anandar College, Karumathur, Madurai, \\ Tamil Nadu 625514, India \\ ${ }^{f}$ Biology Department, Faculty of Science and Arts in Dahran Aljnoub, King Khalid \\ University, Abha, Saudi Arabia \\ ${ }^{\mathrm{g}}$ Research Center for Advanced Materials Science (RCAMS), King Khalid University, Abha, \\ Kingdom of Saudi Arabia \\ ${ }^{\mathrm{h}}$ Agriculture Research Centre, Soil, Water and Environment Research Institute, Giza, Egypt \\ * Corresponding Author: R. Ganesan \\ (E-mail address: gans@iisc.ac.in)
}

\section{Abstract:}

In this report, we have discussed the performance of highly sensitive CdSe based photodetector. The CdSe thin films were prepared by thermal evaporation method on the cleaned glass substrate at room temperature. The influence of post annealing on the optical, morphological, structural and photo-electrical properties at different temperatures were investigated. The formation of polycrystalline $\mathrm{CdSe}$ films was confirmed from X-ray diffraction (XRD) and Raman studies. The change in surface morphology along with the average grain size of films were observed by field emission scanning electron microscopy (FESEM). The stoichiometric ratio of $\mathrm{Cd}$ and Se elements in the deposited films was verified from Energy dispersive X-ray spectroscopy (EDS). The change in various optical parameters like absorption coefficient $(\alpha)$, extinction coefficient $(\mathrm{k})$, optical band gap $\left(E_{\mathrm{g}}\right)$, refractive index (n) etc. of the studied films were calculated from the UV-Visible measurement. Importantly, the band gap values were decreased and increased with different annealing temperatures. The $\mathrm{CdSe}$ film annealed at $300{ }^{\circ} \mathrm{C}$ showed good photo-response and the corresponding optical properties which make them suitable for photodetector applications.

Keywords: photodetector, CdSe, band gap, refractive index 


\section{Introduction}

In the recent years, several numbers of studies were done on the novel properties of chalcogenide-based semiconductors (band gap between 1-3 eV) as they found applications in many optoelectronic devices [1-3]. In particular, Cadmium Selenide (CdSe) is a part of II-VI elemental group and leading semiconducting alloy due to its direct band gap $(\sim 1.74 \mathrm{eV}$ at room temperature), good absorption ability, cost effective, p-type conductivity, and excellent photosensitivity [4]. At present, researchers are focused on the development of CdSe based photodetector due to its high performance of photo sensing capability under visible to near IR radiation [5]. The photo-response of the CdSe film mainly depends on the photo generation and/or electron-hole pair recombination by the adsorption of higher incident power energy than the energy gap of the material and also the separation of electro-hole pairs by the external electric fields. Therefore, a CdSe photo-sensing behaviour can possibly enhanced by changing its band gap by tuning different parameters such as, different nanostructures, doping element, growth level, post annealing, etc. Especially annealing could play an important role for enhancing the photoelectric performance because, temperature can change the nanostructure shapes (grain sizes) and reduce the grain boundaries [6].

The physical and chemical properties of CdSe were mainly depending on the deposition conditions and techniques employed in the preparation of the films. In the past few decades, a number of deposition methods were used to fabricate CdSe film, like magnetron sputtering, thermal evaporation, spray pyrolysis, SILAR, chemical bath deposition (CBD) and electro deposition [7-9]. Among them, thermal evaporation is one of the most convenient and high vacuum assisted technique for obtaining uniform film. Also, the thermally evaporated semiconducting films have good mechanical stability due to its high-level of adhesion to the substrate. The rate of deposition was easily controlled by changing its power, 
time duration of deposition, concentration of the powder and different substrate; also, it is used for large area thin film for wide range of industrial applications.

Some of the works related to CdSe photodetectors were investigated recently. Jiang et al. [10] prepared the CdSe nanoribbons in horizontal quartz tube by using the simple thermal evaporation technique, and they found the increase of photocurrent but decrease in the response time due to the reduction of recombination centers. Singh et al. [11] reported the solution processed CdSe nanowire $(\mathrm{NW})$ and found the responsivity and detectivity are 0.1 $\mathrm{AW}^{-1}$ and $3.1 \times 10^{9}$ (jones) respectively. Also, the responsivity was increased by the increase of bias voltage from 1 to $35 \mathrm{~V}$. Kung et al. [12] studied the CdSe nanowire for tunable photo detection sensitivity by using the lithographically patterned nanowire prepared by electro deposition method and the observed responsivity value was $1.7 \mathrm{AW}^{-1}$. Shelke et al. [13] reported the spray deposited CdSe films for visible spectral photodetector with the narrow band gap of $1.75 \mathrm{eV}$. The prepared photodetector showed high responsivity of $4.9 \mathrm{AW}^{-1}$ for its direct optical band gap with very fast response time of $12 \mathrm{~ms}$. Based on the previous reports, we strongly believe that $\mathrm{CdSe}$ based semiconducting films will perform well in photo sensor device fabrication under visible light radiation.

Herein, we have demonstrated the CdSe thin films prepared by thermal evaporation method at room temperature. Further, the as-deposited films were annealed at $100^{\circ} \mathrm{C}, 200^{\circ} \mathrm{C}$, $300^{\circ} \mathrm{C}$ and $400^{\circ} \mathrm{C}$. The as-deposited and annealed films were characterized by different experimental techniques to investigate the optical, structural, surface morphological, and photo response properties. Mainly, we have studied the photo sensing performance with the help of $532 \mathrm{~nm}$ laser. The influence of post annealing on photo detectivity, external quantum efficiency and responsivity of the films were calculated and reported in the present work. In addition, we have briefly studied and reported the linear and non-linear optical properties of the CdSe films for the first time. 


\section{Experimental with characterizations}

The nanostructured CdSe films were deposited onto cleaned glass substrates at room temperature (RT) by using CdSe powder as an evaporation source material in thermal evaporation technique. The film deposition was done on $10 \mathrm{~cm} \times 10 \mathrm{~cm}$ glass substrate and for large scale commercial application, the deposition can be done by varying the vacuum chamber. In brief, the deposition chamber was evacuated at $1 \times 10^{-5}$ Torr. The deposited films were post annealed at $100{ }^{\circ} \mathrm{C}, 200{ }^{\circ} \mathrm{C}, 300{ }^{\circ} \mathrm{C}$, and $400{ }^{\circ} \mathrm{C}$ respectively under nitrogen gas atmosphere. The topographical (top view), thickness (cross-sectional view) and elemental composition of the films were examined by FESEM (Carl Zeiss Ultra 55) and EDS (Oxford Instruments $50 \mathrm{~mm}^{2}$ ). The structural behaviour of the films were studied with X-ray diffractometer (XRD) (Rigaku MiniFlex 600) and Raman spectroscopy. The optical data were recorded at room temperature by using a UV-Vis spectrometer (SpectraPro2300i) in the spectral range of $200-1100 \mathrm{~nm}$. The photo-electrical responses of the fabricated films were measured by Xenon arc lamp as a light source (Nova P/N 7Z01500, Ophir) and Keithley 2450 as a source meter.

\section{Results and Discussion}

\subsection{Structural analysis by XRD}

Fig. 1 shows the XRD patterns of the as-deposited and different annealed (from $100^{\circ} \mathrm{C}$ to $\left.400{ }^{\circ} \mathrm{C}\right) \mathrm{CdSe}$ thin films. The most intense peak observed at $2 \theta=25.42^{\circ}$ corresponds to (002) plane and the low intensity peak at $2 \theta=45.90^{\circ}$ represents (103) plane. The XRD pattern clearly indicates the polycrystalline nature with hexagonal structure (JCPDS No. 08-0459) of the deposited CdSe films [14]. The peak intensity initially increased up to $300{ }^{\circ} \mathrm{C}$ annealed film and then it was reduced for higher annealing temperature films. In general, annealing can enhance the grain growth level in to the native lattice due to the reason that periodical arrangement of atoms gets high energy at a particular lattice plane. 
Consequently, there is an increasing trend of peak intensity along with increasing annealing temperature. The experimental d-values were calculated from Bragg's relation.

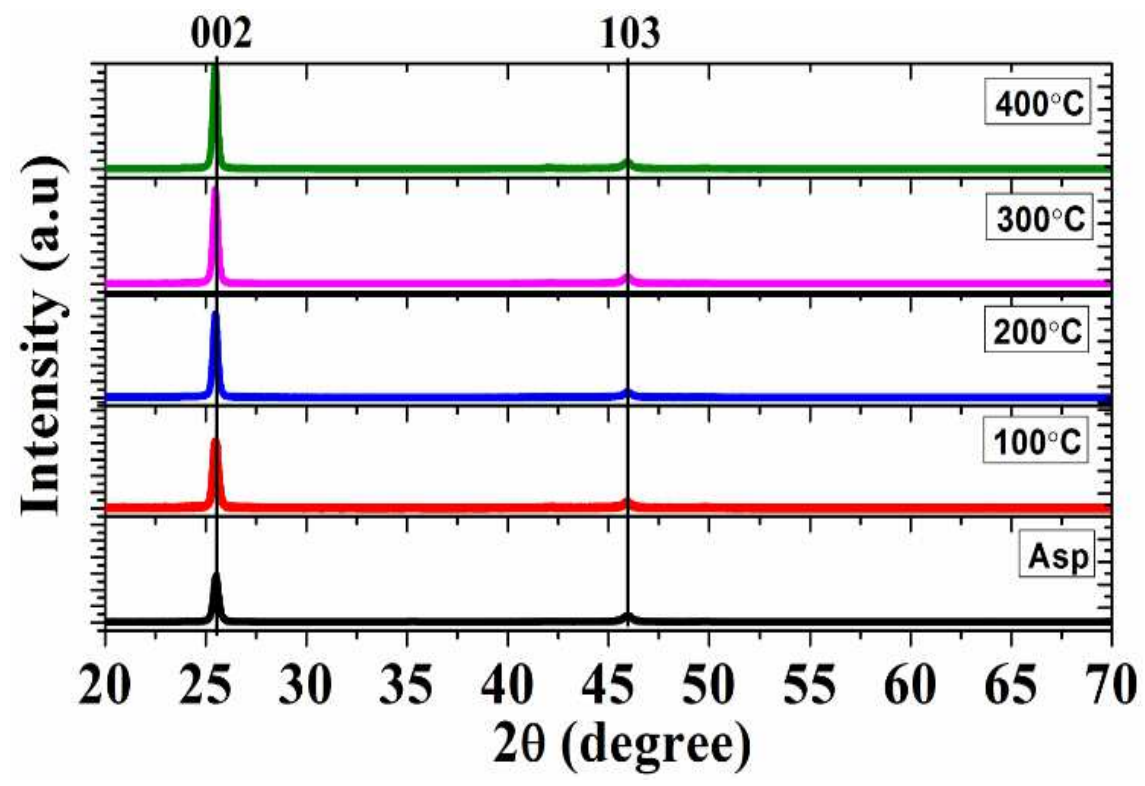

Fig. 1. XRD pattern of CdSe thin films for as-deposited and different annealing temperature The average crystallite size of the prepared films $(\sim 12$ to $100 \mathrm{~nm})$ were calculated using Scherrer' formula and the obtained values are listed in table S1 (supplementary table). The obtained crystallite size was increased from $24 \mathrm{~nm}$ to $28 \mathrm{~nm}$ for (002) plane and $12 \mathrm{~nm}$ to 14 $\mathrm{nm}$ for (103) plane respectively. Thus, the increase in crystallinity of the films with the increase in annealing temperature leads decrease the FWHM value. Moreover, there is no identified impurity peaks related to $\mathrm{CdO}$ or others observed from the figure confirming the phase purity of $\mathrm{CdSe}$ with respect to increasing annealing temperature.

\subsection{Raman analysis}

Raman spectroscopy gives information regarding vibrational, electronic states, structural and phonon properties of the materials. The Raman spectra of CdSe films were recorded in the range of $100-500 \mathrm{~cm}^{-1}$ at room temperature. The standard Raman spectrum of the bulk CdSe sample shows peaks at $210 \mathrm{~cm}^{-1}$ and its overtone at $418 \mathrm{~cm}^{-1}$ which are refered to the longitudinal optical phonon mode (LO mode) [15]. In the present study, Fig 2. 
shows the Raman spectrum of both annealed and as-prepared CdSe thin films. The two strong visible peaks at $203 \mathrm{~cm}^{-1}$ and $407 \mathrm{~cm}^{-1}$ are due to the confinement of optical phonons in the films. The $1^{\text {st }}$ order LO phonon modes are present at $203 \mathrm{~cm}^{-1}$ and there is a shift of $6 \mathrm{~cm}^{-1}$ in the wavenumber as compared to the earlier reported values. Similarly, the $2^{\text {nd }}$ order LO phonon modes are present at $407 \mathrm{~cm}^{-1}$ and there is a shift of $3 \mathrm{~cm}^{-1}$ as compared with the earlier reports. Such small Raman shift observed for both LO and 2LO modes might be due to the strain created in CdSe layers during deposition time [16]. This small change in wave number and LO mode peak broadening may be due to the change in crystallite size of the prepared films. It was observed that the intensity of this peak increased than the as-prepared one with annealing which shows the increase of $\mathrm{Cd}-$ Se bonds due to the annealing effect. In addition, all the films have one shoulder peak at around $164 \mathrm{~cm}^{-1}$ that corresponds to the contribution of surface optical (SO) vibrations attributed due to phonon confinement [17]. Dzhagan et al. noticed the same surface optical mode at $167 \mathrm{~cm}^{-1}$ for CdSe nanocrystals [18].

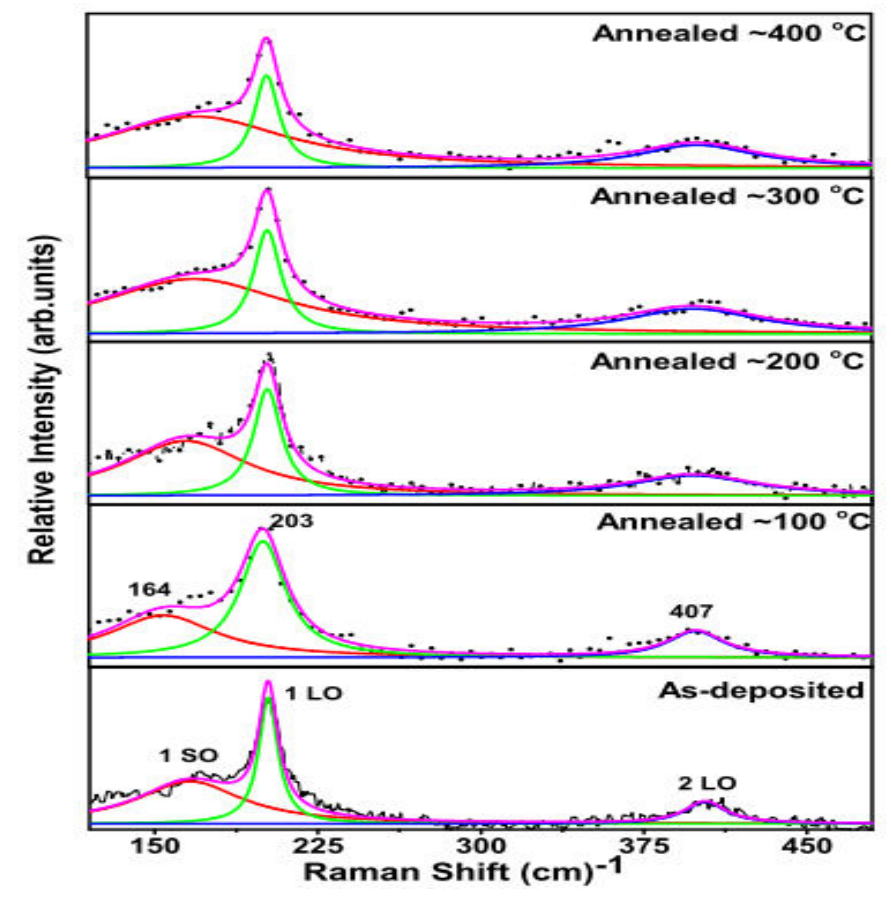

Fig. 2 Raman spectra of thermal evaporated CdSe thin films with different annealing temperature 


\subsection{Morphological and compositional analysis}

Figure 3 (a-e) shows the FESEM micrographs of as-prepared and post annealed CdSe films. The surface of the film describes the deposited film uniformity (free from pin holes and cracks) and regular barley shape grain characteristics. Also, it clearly shows that the average grain size increased with annealing temperatures and the layers became dense with reduced film thickness ( $900 \mathrm{~nm}$ to $720 \mathrm{~nm})$ as given in Figure $4(\mathrm{a}, \mathrm{b})$. Due to the increase in the heat treatment on the materials, the film thickness might have decreased due to the reduction of grain boundaries; resulting the increase of photoelectric performance. Figure $4 \mathrm{c}$ presents the elemental compositions of different annealed CdSe thin films. It reveals that as a function of annealing temperatures, there was no significant change observed in their material stoichiometry. A shoulder peak originated at $3.2 \mathrm{keV}$ which is indicating the characteristics $\mathrm{L}$ element peak of $\mathrm{Cd}$.
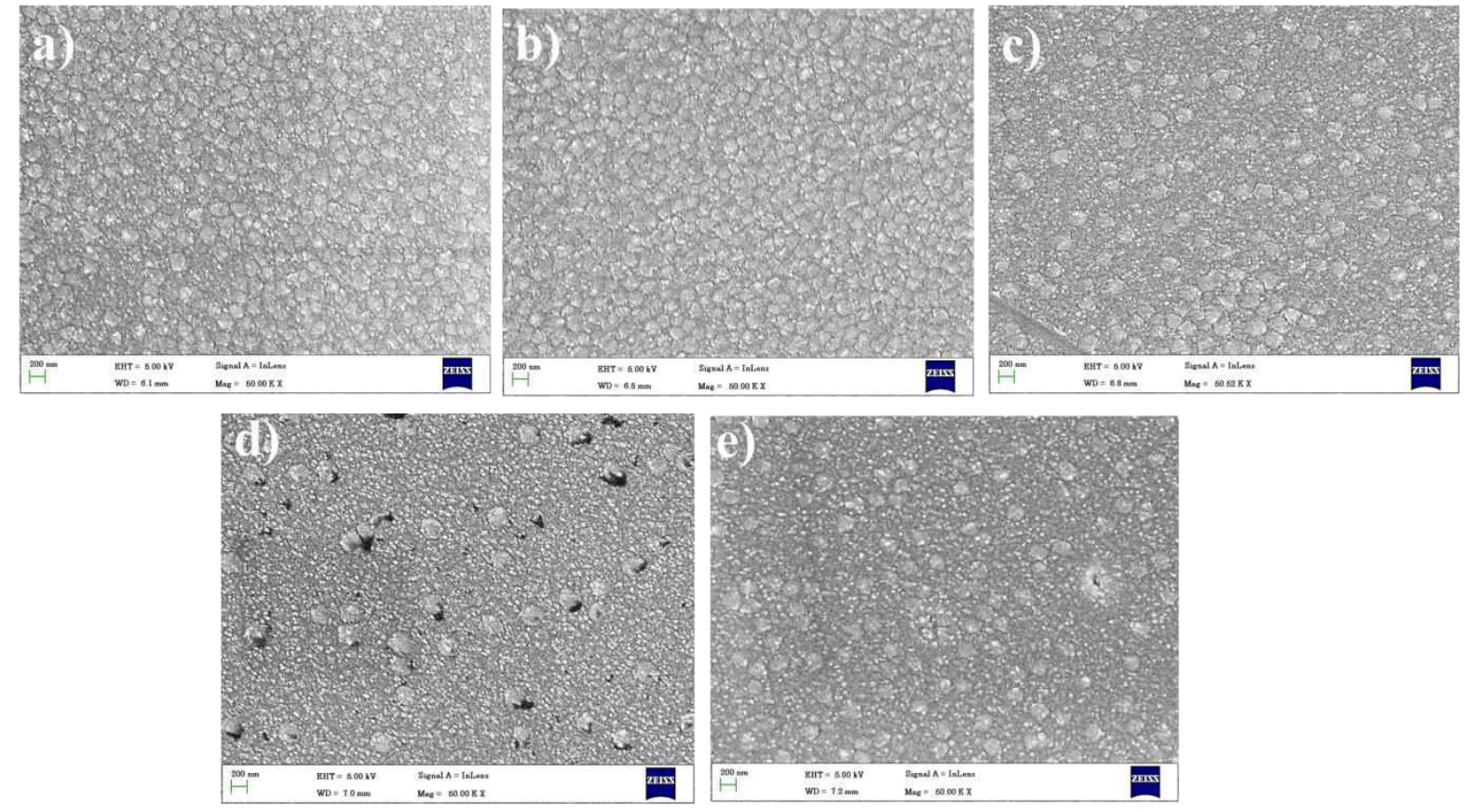

Fig.3. FESEM images of (a) as-deposited and annealed at (b) $100{ }^{\circ} \mathrm{C}$, (c) $200{ }^{\circ} \mathrm{C}$, (d) $300{ }^{\circ} \mathrm{C}$ and (e) $400{ }^{\circ} \mathrm{C}$. 

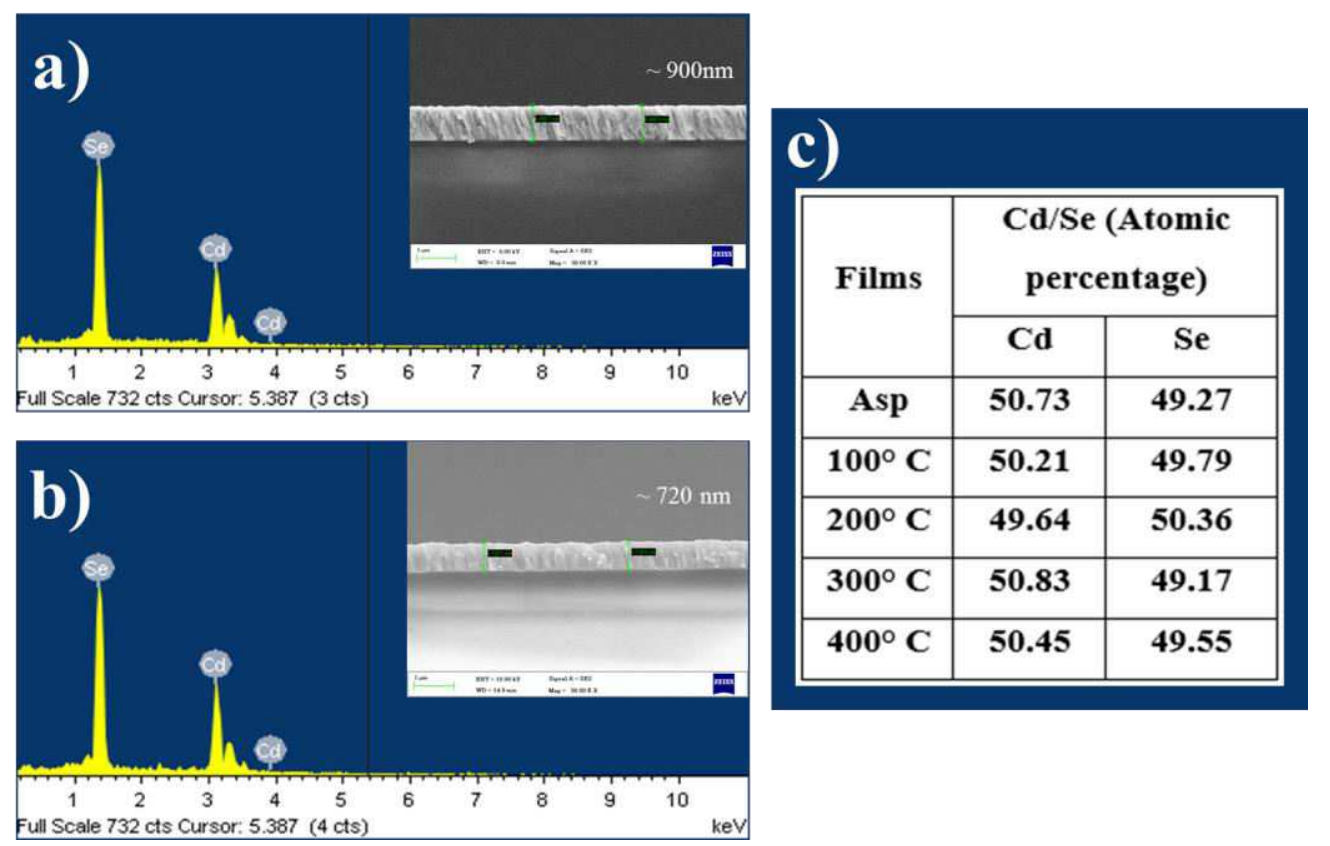

Fig.4. EDS images of (a) as-deposited and (b) $300{ }^{\circ} \mathrm{C}$ annealed CdSe thin films, (c) elemental composition of each film

\section{4 . Linear and non-linear optical properties}

\subsubsection{Transmittance, absorbance, band gap}

To evaluate the linear optical parameters like as absorption, optical energy gap $\left(\mathbf{E}_{\mathbf{g}}\right)$ and linear refractive index $(n)$, the optical transmittance (T) spectra were collected and plotted in Fig. 5(a). The presence of fringes is because of the interference between the substrate and film surface which shows the homogeneity and smooth nature of the prepared films [19]. The transmitting power of the annealed film decreased and is lowest for the 300 ${ }^{\circ} \mathrm{C}$ annealed film as compared to the as-prepared films. The variation in transmission is due to the different degree of electronic polarizability in the annealed films. This behaviour also indicates the reduction in the transmittance of the film through introducing the structural defects. The optical absorbance spectra of different films are shown in Fig. 5(b) that indicates the rise in absorption capacity of the annealed films. The highest absorption is shown by the $300{ }^{\circ} \mathrm{C}$ annealed film which is a potential film as good photodetector. 

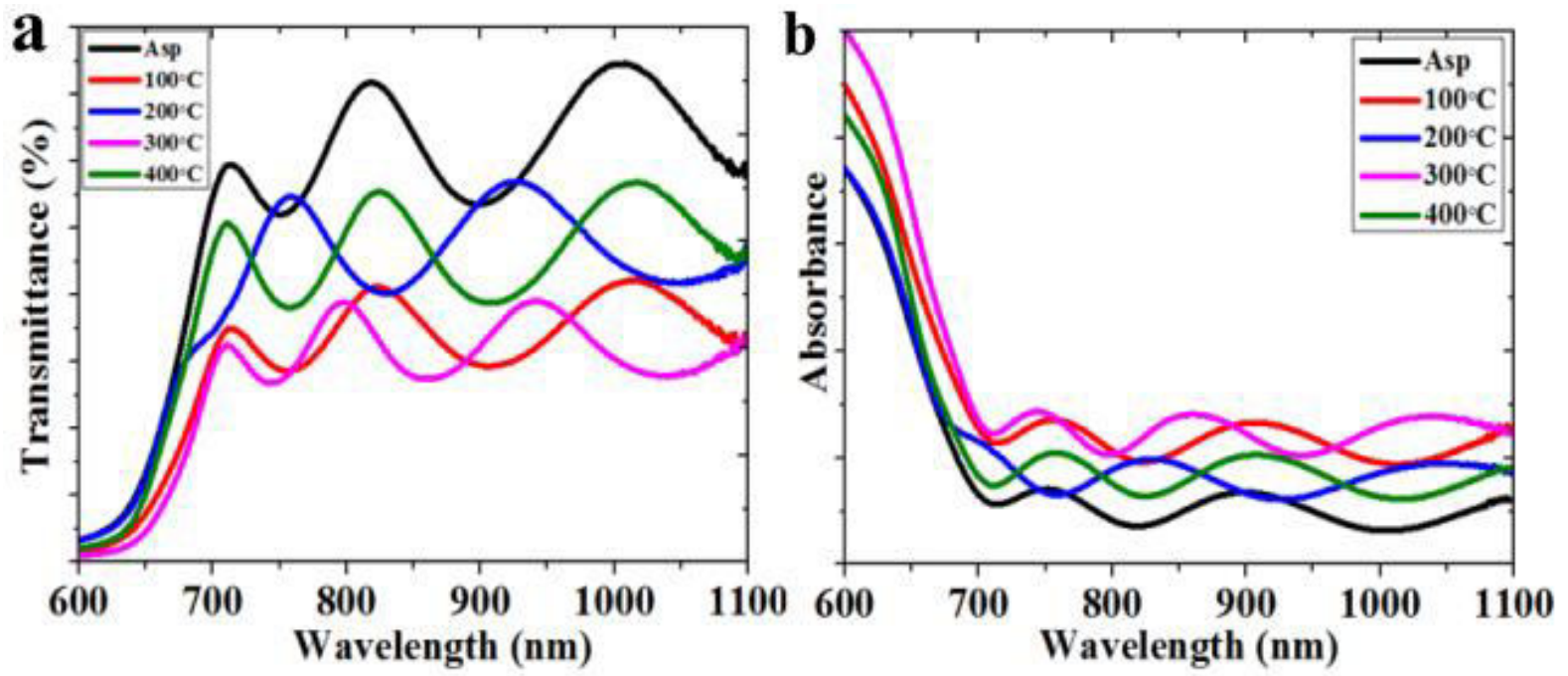

Fig. 5 (a) Transmission and (b) absorbance spectra of as-prepared and annealed thin films

The fundamental absorption edge for the investigated films has been analysed to know the kind of optical transition and the optical energy gap value $\left(E_{g}\right)$. The related information regarding band gap was calculated from the high absorption region $\left(\alpha \geq 10^{4} \mathrm{~cm}^{-}\right.$ $\left.{ }^{1}\right)$ by Tauc relation [20].

$$
(\alpha h v)=B\left(h v-E_{g}\right)^{m}
$$

where $\mathrm{B}$ is the Tauc parameter and depends on the transition probability, $\mathrm{h}$ and ' $\mathrm{v}$ ' are Planck's constant the frequency of the incident photon respectively. The power ' $m$ ' possesses different values like $1 / 2,2,3 / 2$ and 3 to determine the kind of electronic transitions. The values are for direct allowed (1/2), indirect allowed (2), direct forbidden (3/2) and indirect forbidden (3) transitions respectively [21]. The obtained data were fitted best for $\mathrm{m}=1 / 2$ which shows the transition in the studied films is of direct allowed type. Fig. 6 shows the plot between $(\alpha h v)^{2}$ vs ' $h v$ ' in which the X-intercept gives the value of optical band gap. The bandgap of as-prepared film was $1.996 \mathrm{eV}$ which increased upon annealing as shown in Table 1. This increase in $\mathrm{E}_{\mathrm{g}}$ is well explained by Davis and Mott [22] based on on the concept of density of state. The thermal energy given to the films annealed out the defects and thus the degree of disorder reduced. So, the decrease in the density of defects reduces the width of 
the localized states for which the band gap increased for the annealed films. The $300{ }^{\circ} \mathrm{C}$ annealed film possesses the band gap of $2 \mathrm{eV}$ which is good for visible photo detection performance.

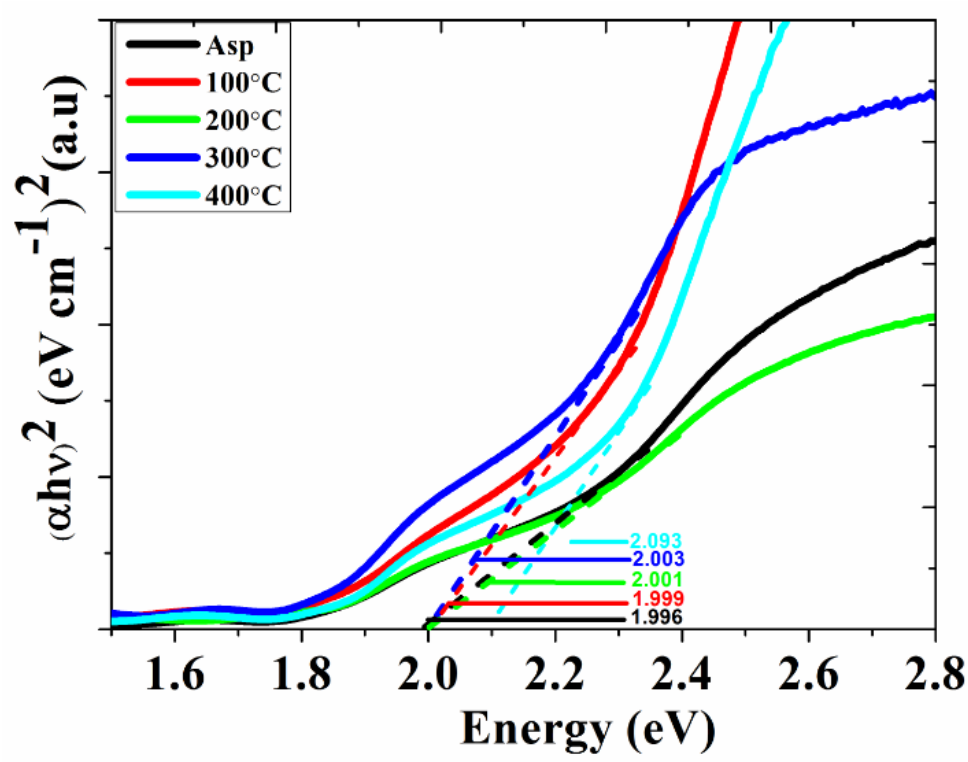

Fig. 6.Optical band gap of the prepared CdSe thin films with different annealing temperatures

\subsubsection{Linear Refractive index (n)}

The first approximated refractive index $\left(\mathrm{n}_{1}\right)$ was evaluated by Swanepoel's envelope method [23] in the weak and moderate absorption region by the equation;

$$
\begin{gathered}
n_{1}{ }^{2}=\left[N+\left(N^{2}-S^{2}\right)^{1 / 2}\right] \\
\text { where; } \quad N=2 S\left(\frac{T_{M}-T_{m}}{T_{M} T_{m}}\right)+\left(\frac{S^{2}+1}{2}\right)
\end{gathered}
$$

where, $T_{M}$ and $T_{m}$ and are the maxima and minima of transmittance at certain $\lambda$ and ' $S$ ' represents the glass substrate refractive index (1.51). The actual linear refractive index (n) of the films at different ' $\lambda$ ' values was evaluated and presented in Fig. 7. The value of ' $n$ ' decreased with wavelength as shown in figure 7 which shows the normal dispersion behavour of the films. It has been observed that the refractive index varies for different annealing temperatures and is more for the $300{ }^{\circ} \mathrm{C}$ annealed film. The increase in refractive index can be interpreted for the increase in polarizability $\left(\alpha_{p}\right)$ values [24]. Since, the increase in 
polarizability increases the light polarization which leads to the increase in photocurrent in the materials like $\mathrm{Bi}_{2} \mathrm{Te}_{3}[25]$.

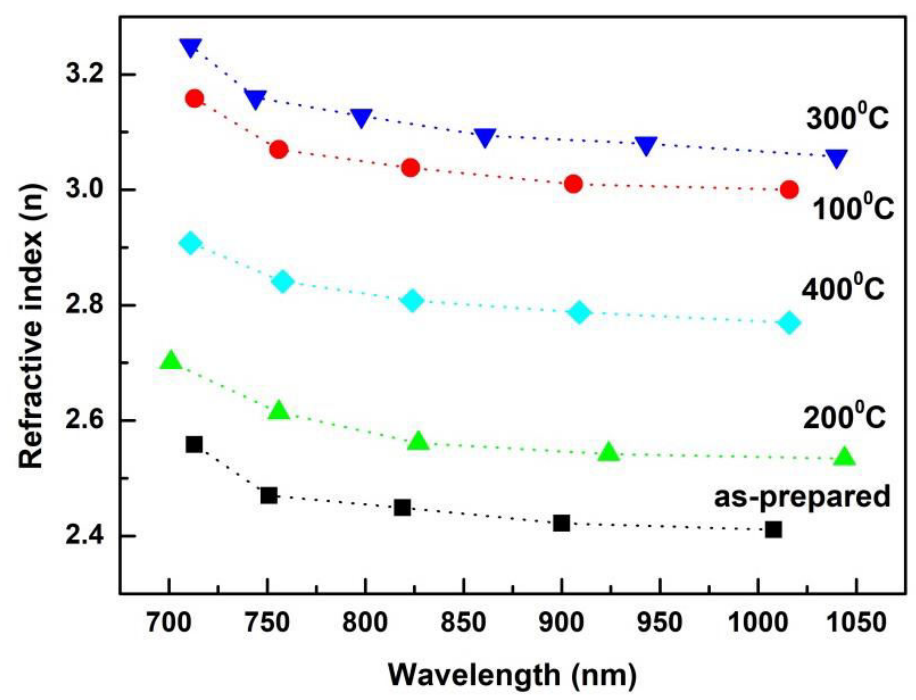

Fig. 7. Change in refractive index (n) vs wavelength for different annealing temperatures

\subsubsection{Single oscillator energy $\left(E_{0}\right)$ and Dispersion energy $\left(E_{d}\right)$}

The dispersion parameters of the thin films give useful information's about its optical behaviour. These parameters are essential for designing spectral analysis devices in optical communications. The concept of single-effective-oscillator model proposed by Wemple-Di Domenico (WDD) [26] was used to measure the dispersion of $\mathrm{n}(h v)$. The dispersion of ' $\mathrm{n}$ ', below the absorption band gap $\left(h v<E_{g}\right)$, relates the dispersion energy $\left(E_{d}\right)$ and single oscillator energy $\left(E_{o}\right)$ by using the relation [27].

$$
n^{2}(h v)-1=\frac{E_{d} E_{0}}{E_{0}^{2}-h v^{2}}
$$

The dispersion study gives two important quantities such as; effective single oscillator energy $\left(\mathrm{E}_{0}\right)$ and dispersion energy $\left(\mathrm{E}_{\mathrm{d}}\right)$. The $\mathrm{E}_{0}$ gives information regarding the overall band structure of the films that is completely different from $E_{g}$ and also average excitation energy for electronic transitions. Similarly, dispersion energy ' $E_{d}$ ' presents the oscillator strength which is related to the inter band optical transition. $E_{d}$ measures the average intensity of the inter-band optical transitions, which depends on chemical bonding and charge distribution 
within each unit cell. Fig. 8(a) shows the plot between $\left(n^{2}-1\right)^{-1}$ vs $(\mathrm{h} v)^{2}$ and the straightline fitting gives the intercept as $\frac{E_{0}}{E_{d}}$ and slope as $\left(E_{0} E_{d}\right)^{-1}$. The $\mathrm{E}_{0}$ and $\mathrm{E}_{\mathrm{d}}$ values were calculated from the slope and intercept which are given in Table 1. The value of $E_{0}$ and $E_{d}$ are found to be changed with different annealing conditions and more for the $300{ }^{\circ} \mathrm{C}$ annealed film. This film is having high oscillator strength which is more stable for the photo detection. The oscillator strength, $f=E_{0} E_{d}$ is presented in Table 1 that shows the highest strength of the film at $300{ }^{\circ} \mathrm{C}$ annealing. The static refractive index (i.e. $n$ at $h v=0$ ) was calculated from the formula

$$
\varepsilon_{\infty}=n_{0}^{2}=\left(1+\frac{E_{d}}{E_{0}}\right)
$$

The $\mathrm{n}_{0}$ value increased like the linear refractive index (n) as shown in Table 1 which is responsible for the change in nonlinear optical parameters [28].
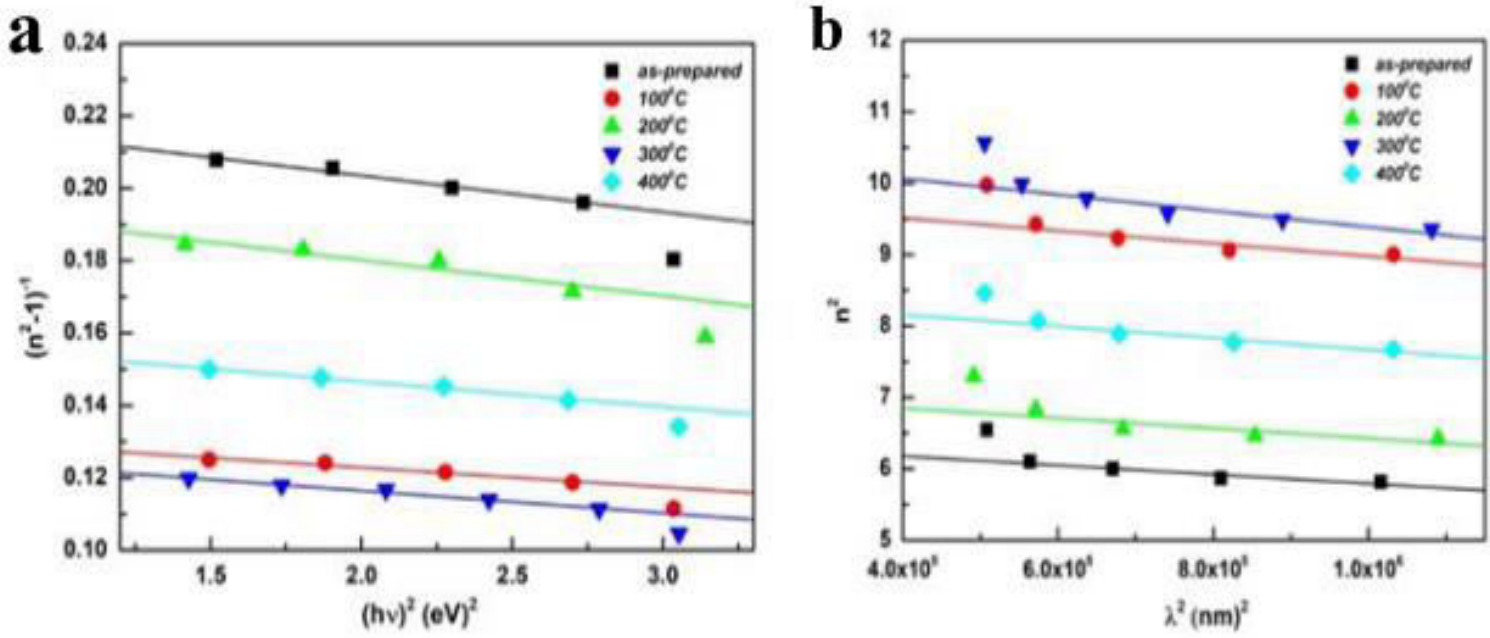

Fig.8 (a) plot of $\left(n^{2}-1\right)^{-1}$ vs $(h v)^{2}$ for calculation of $E_{0}$ and $E_{d}$ and (b) plot of $n^{2}$ vs $\lambda^{2}$ to calculate $\mathrm{N} / \mathrm{m} *$ for the as-deposited and different annealed films

(iii) High frequency dielectric constant $\left(\varepsilon_{L}\right)$ and carrier concentration $\left(\mathrm{N} / \mathrm{m}^{*}\right)$

In order to evaluate the high frequency dielectric constant $\left(\varepsilon_{\infty}\right)$ and carrier concentration $\left(\mathrm{N} / \mathrm{m}^{*}\right)$ in the films, the following formula was used. [29].

$$
\varepsilon_{1}=n^{2}=\varepsilon_{L}-\left(\frac{e^{2} N}{4 \pi^{2} c^{2} \varepsilon_{0} m^{*}}\right) \lambda^{2}
$$


where $\varepsilon_{1}, \mathrm{e}, \mathrm{N}, \varepsilon_{0}, \mathrm{~m}^{*}$ and $\mathrm{c}$ denotes the real part of the dielectric constant, charge of electron, free charge carrier concentration, permittivity of free space, effective mass of charge carrier and velocity of light respectively. The linear fitting of the plot between $n^{2}$ vs $\lambda^{2}$ as shown in Fig. 8(b) gives $\varepsilon_{\mathrm{L}}$ as intercept and $\mathrm{N} / \mathrm{m}^{*}$ was calculated from the slope. The obtained values of $\varepsilon_{\infty}, \boldsymbol{\varepsilon}_{\mathbf{L}}$ and $\mathrm{N} / \mathrm{m}^{*}$ for the films are presented in Table 1 . It shows that the value of $\varepsilon_{\mathrm{L}}$ varies with variation in the carrier concentration. Though $\varepsilon_{L}$ and $\varepsilon_{\infty}$ represents the same high frequency dielectric constant, but the dissimilarity is because of the change in carrier concentration which could be due to the increase in lone-pair electrons of Se atoms. The $\varepsilon_{\mathrm{L}}>\varepsilon_{\infty}$ is due to the increase in free charge carrier concentration in the films [30]. The $300{ }^{\circ} \mathrm{C}$ annealed film is having the high value of carrier concentration which is good for the photodetector.

\subsubsection{Optical conductivity $\left(\sigma_{\text {opt }}\right)$ and electrical conductivity $\left(\sigma_{\text {elec }}\right)$}

The optical and electronic behaviour of the films were evaluated by calculating the optical conductivity $\left(\sigma_{o p t}\right)$ and electronic conductivity $\left(\sigma_{\text {elec }}\right)$ with the formula involving absorption coefficient $(\alpha)$ and refractive index $(n)[31,32]$.

$$
\sigma_{o p t}=\frac{\alpha n c}{4 \pi}, \quad \sigma_{e l e c}=\frac{\lambda n c}{2 \pi}
$$

The optical conductivity $\left(\sigma_{\mathrm{opt}}\right)$ gives information about the electronic state of the materials. Fig. 9(a) depicts the decrease of $\sigma_{o p t}$ with annealing temperature and also increase in wavelength. The high value of $\sigma_{o p t}$ for the $300{ }^{\circ} \mathrm{C}$ annealed film is due to the high value of absorption coefficient and linear refractive index. However, the increase in $\sigma_{\text {opt }}$ at $300{ }^{\circ} \mathrm{C}$ annealing assures high photo-response and increment of electrons excitation of the films under consideration. The Fig. 9(b) shows the variation of $\sigma_{\text {elec }}$ at different annealing temperatures which shows completely different behaviors than that of optical conductivity. 
The $\sigma_{\text {elec }}$ increased with wavelength and shows variation with annealing temperature. Again, the $300{ }^{\circ} \mathrm{C}$ annealed film is having the highest electrical conduction.
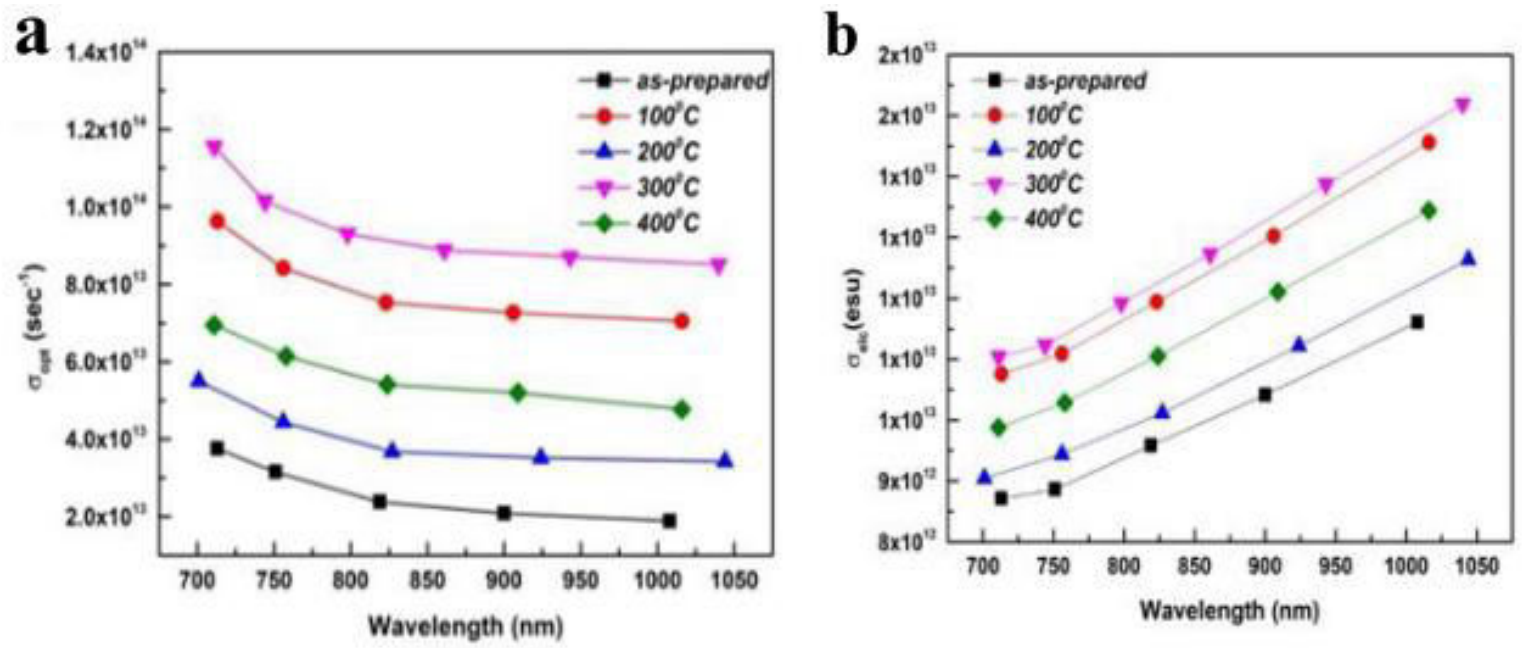

Fig. 9 Variation of (a) optical conductivity $\left(\sigma_{\text {opt }}\right)$ and (b) electrical conductivity $\left(\sigma_{\text {ele }}\right)$ with different annealing temperature

\subsubsection{Nonlinear optical assessments}

The nonlinear optical behaviour of the films is due to the change of the nonlinear polarization signal of a material to the incident radiation which plays an important role in nonlinear optics in recent years. The polarization of the material system is expressed in terms of nonlinearity and well evaluated by utilizing semi-empirical relations involving the film's refractive indices. The $3^{\text {rd }}$ order nonlinear optical susceptibility $\left(\chi^{(3)}\right)$ is an important factor that decides the of use of a particular material in nonlinear photonic devices [33]. The nonlinear refractive index ' $n_{2}$ ' is the material's disproportionate response to the applied electric field. Tichy et al. [34] formulated a rule that takes the linear refractive index ' $n$ ' values and WDD parameters to evaluate the value of $\chi^{(\mathbf{3})}$ and ' $n_{2}$, by using the following formulas [35]:

$$
\chi^{(3)} \cong \mathrm{A}\left(\chi^{(1)}\right)^{4} \quad \text { (7) } \quad\left\{\text { where } \mathrm{A}=1.7 \times 10^{-10}(\chi \text { measured in esu })\right\}
$$

In the long wavelength limit $(\mathrm{h} v \rightarrow 0)$, the above equation becomes 


$$
\chi^{(1)}=\left(\mathrm{n}_{0}^{2}-1\right) / 4 \pi
$$

The ' $\mathrm{n}_{2}$ ' is related to the third-order susceptibility $\chi^{(3)}$ by the relation

$$
n_{2}=\frac{12 \pi \chi^{(3)}}{n_{0}}
$$

The obtained parameters are given in Table 1 that shows the changes with annealing temperature which is due to the different degree of polarization with annealing. The $300{ }^{\circ} \mathrm{C}$ annealed film is having the highest values of nonlinear parameters that makes the material as diffraction free and potential candidate for photodetector.

\begin{tabular}{|c|c|c|c|c|c|}
\hline Optical parameters & As-prepared & $100{ }^{0} \mathrm{C}$ & $200^{0} \mathrm{C}$ & $300^{0} \mathrm{C}$ & $400^{\circ} \mathrm{C}$ \\
\hline Thickness (nm) & 900 & 837.1 & 828.7 & 720 & 703.6 \\
\hline Band gap $\left(E_{g}\right) e V$ & 1.996 & 1.999 & 2.001 & 2.003 & 2.093 \\
\hline $\begin{array}{l}\text { Dispersion or strength } \\
\text { energy, } E_{d}(e V)\end{array}$ & 21.10 & 34.57 & 22.46 & 38.65 & 29.85 \\
\hline $\begin{array}{l}\text { Effective single oscillator } \\
\text { energy, } E_{o}(e V)\end{array}$ & 4.72 & 4.75 & 4.49 & 4.98 & 4.79 \\
\hline Oscillator strength $\mathrm{f}=\mathrm{E}_{\mathrm{d}} \mathrm{E}_{0}$ & 99.59 & 164.2 & 100.84 & 192.47 & 142.98 \\
\hline Static refractive index $\left(\mathrm{n}_{0}\right)$ & 2.33 & 2.87 & 2.44 & 2.96 & 2.68 \\
\hline $\begin{array}{l}\text { High frequency dielectric } \\
\text { constant } \varepsilon_{\infty}=\mathrm{n}_{0}^{2}\end{array}$ & 5.428 & 8.23 & 5.953 & 8.761 & 7.182 \\
\hline $\begin{array}{l}\text { Dielectric constant of the } \\
\text { lattice }\left(\varepsilon_{\mathrm{L}}\right)\end{array}$ & 6.43 & 9.87 & 7.13 & 10.52 & 8.49 \\
\hline $\begin{array}{l}\text { Carrier concentration }\left(\mathrm{N} / \mathrm{m}^{*}\right) \\
\text { in } \mathrm{cm}^{3} \mathrm{gm}\end{array}$ & $7.82 \times 10^{38}$ & $10.94 \times 10^{38}$ & $8.58 \times 10^{38}$ & $13.86 \times 10^{38}$ & $10.08 \times 10^{38}$ \\
\hline $\begin{array}{l}\text { First order nonlinear optical } \\
\text { susceptibility }\left(\chi^{1}\right)\end{array}$ & 0.353 & 0.576 & 0.394 & 0.618 & 0.492 \\
\hline $\begin{array}{l}\text { Third order nonlinear optical } \\
\text { susceptibility }\left(\chi^{3}\right) \text { in esu }\end{array}$ & $2.63 \times 10^{-12}$ & $18.71 \times 10^{-12}$ & $4.09 \times 10^{-12}$ & $24.79 \times 10^{-12}$ & $9.96 \times 10^{-12}$ \\
\hline $\begin{array}{l}\text { Nonlinear refractive index } \\
\left(\mathrm{n}_{2}\right) \text { in esu }\end{array}$ & $4.25 \times 10^{-11}$ & $24.5 \times 10^{-11}$ & $6.31 \times 10^{-11}$ & $31.5 \times 10^{-11}$ & $14.01 \times 10^{-11}$ \\
\hline
\end{tabular}

Table 1: Optical parameters of the prepared CdSe films with different annealing

\subsection{Photodetector analyses}

We have prepared the CdSe based photodetectors for the detection of the visible light radiation for photo-sensor applications. Fig. 10 illustrates the schematic diagram of CdSe film-based photodetector device. To investigate the photoelectric performance, the suitable 
light intensity was vertically incident on the prepared detector and the photocurrent was being observed at room temperature. Contact electrode (silver paste) was used on both sides of CdSe film surface to measure the photocurrent with respect to different bias voltage.

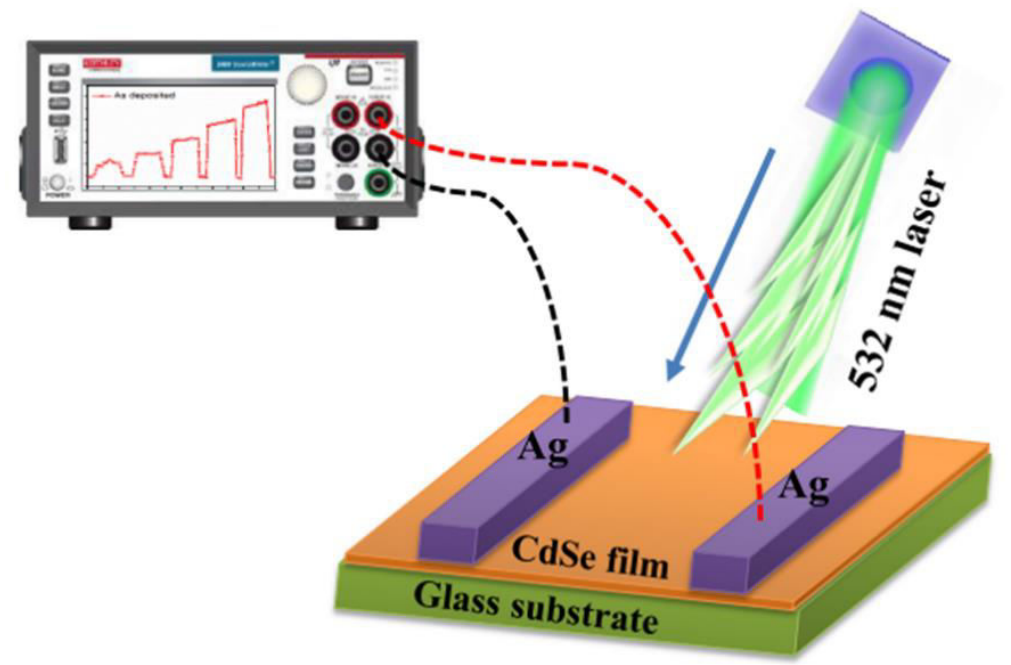

Fig. 10 Schematic diagram of the CdSe photodetector under visible light illumination.

The photocurrent performance of the constructed CdSe detectors were measured using 532 nm light illumination. Fig. 11 shows the typical current-voltage (I-V) characteristics for both in dark and illumination of the CdSe films. The I-V spectra shows that all the prepared films exhibit similar behavior though it differs the order of magnitude with respect to annealing temperature. After illumination, the observed photocurrent value significantly increased with respect to bias voltage and is higher than that of the corresponding dark current. This increase in photocurrent is due to excitation of electron-hole pairs in the CdSe detector as a result, there is an increase of the conductivity. The consistent increase of photocurrent with increasing annealing temperature is attributed to the generation of more electron-hole pairs caused by the decrease of grain boundaries. The highest photocurrent was observed at $300{ }^{\circ} \mathrm{C}$ annealed film due to its low band gap and high crystallinity than that of the other films [36]. In common, the high crystallinity with uniform grains, low band gap and high absorption in the visible spectral line could help to enhance the photo-response for any semiconducting materials. The following investigations are necessary to understand the photoelectric 
performance of the prepared CdSe detector. Responsivity (R) is one of the most important factor for any photodetector. $R$ values were determined from the ratio of induced photocurrent with respect to the power of incident light by the equation [37].

$$
R=\frac{I_{P}}{A \times P_{\text {in }}}
$$

where, $A$ is the area of the prepared CdSe detector, $I_{\mathrm{P}}$ is the photocurrent and $P_{\text {in }}$ is the power of incident light. Figure S1 (supplementary figure) shows the variation of $R$ with respect to different annealed CdSe films and the obtained values were given in table 2. It was found that 

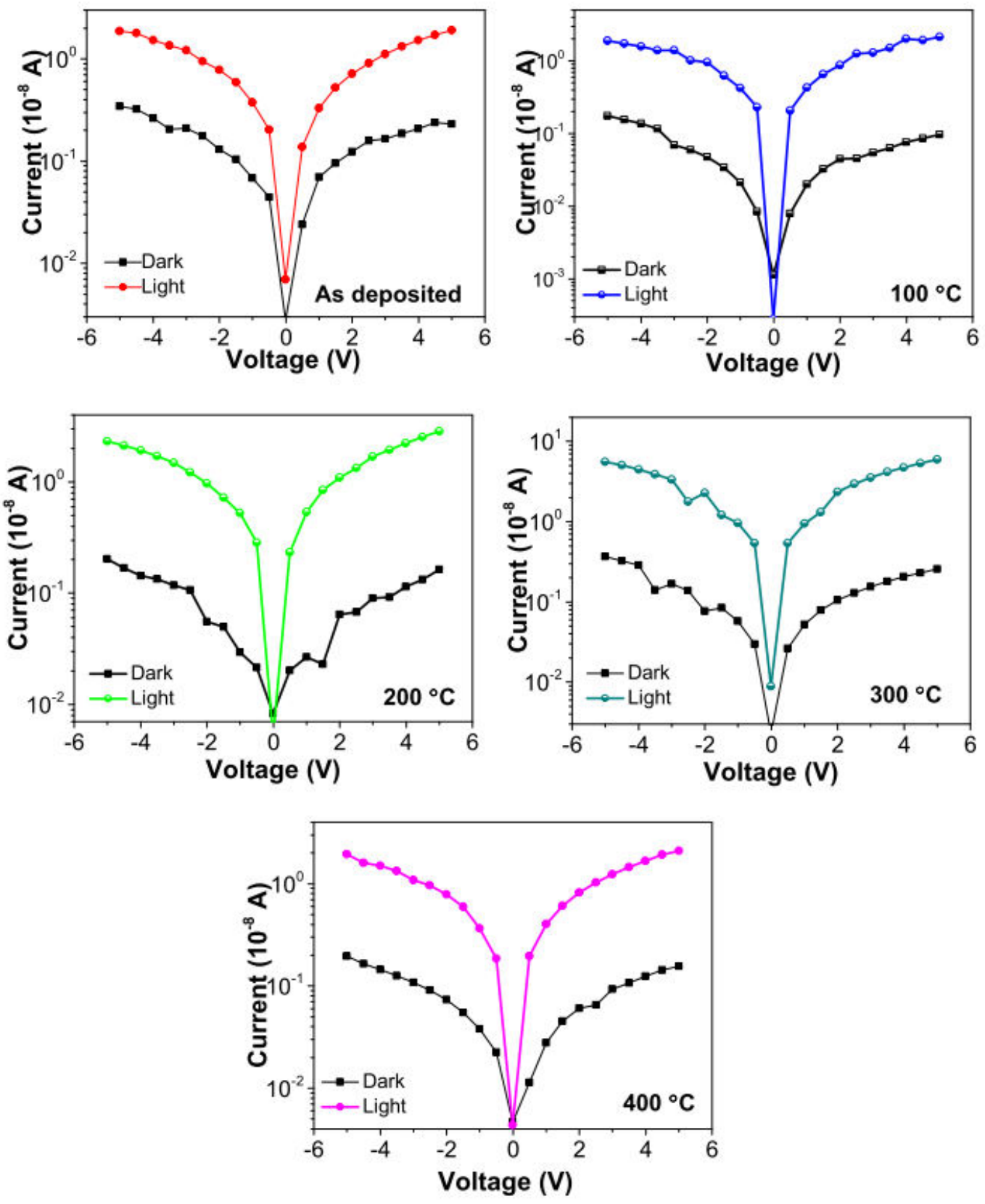

Figure $11 I-V$ characteristics of the fabricated CdSe photodetector measured both in dark and illumination conditions at a bias voltage between $-5 \mathrm{~V}$ and $+5 \mathrm{~V}$.

the values increased from $0.0033 \mathrm{AW}^{-1}$ to $0.011 \mathrm{AW}^{-1}$ for increasing the annealing temperature up to $300{ }^{\circ} \mathrm{C}$ while it reduced slightly to $0.0038 \mathrm{AW}^{-1}$ for higher annealing temperature $\left(400{ }^{\circ} \mathrm{C}\right)$. The observed high $R$ value is due to a higher electron-hole pair 
generation by its low band gap. Previously, Shkir et al. [38] observed the maximum $R$ of 2.71 $\mathrm{AW}^{-1}$ for 5 at. $\%$ Pr doped CdS thin film. Shelke et al. [13] reported the maximum $R$ of 4.9 $\mathrm{AW}^{-1}$ for CdSe thin films at the power intensity of $40 \mathrm{mWcm}^{-2}$ and $0.803 \mathrm{~A} / \mathrm{W}$ for $\mathrm{MoSe}_{2}$ at the power intensity of $40 \mathrm{mWcm}^{-2}$ [39]. In the present work, we observed a maximum responsivity i.e $0.011 \mathrm{AW}^{-1}$ which is reasonable better even at minimum power intensity at 5 $\mathrm{mWcm}^{-2}$. In addition, the responsivity of the annealed film is one order higher than the asdeposited film.

Detectivity $\left(D^{*}\right)$ is one of the other main factors which is used to understand the sensitivity of the CdSe. The higher value of $D^{*}$ indicates the sensible capability in particular light intensity/or corresponding wavelength. The $D^{*}$ can be expressed by the equation [40] using the value of responsivity.

$$
D *=R \sqrt{\frac{A}{2 e I_{d}}}
$$

here, $I_{\mathrm{d}}$ and $e$ represents the dark current and electron charge, respectively. The $D^{*}$ values are given in table 2 and the annealed film exposed the maximum $D^{*}$ value $\left(1.27 \times 10^{10}\right.$ jones $)$ as compared to the as-deposited film $\left(3.88 \times 10^{9}\right.$ jones $)$. The estimated $D^{*}$ value of the prepared $\mathrm{CdSe}$ photodetector is almost close (even at very low power intensity $5 \mathrm{mWcm}^{-2}$ ) to the previous reported value $\left(7.9 \times 10^{11} \mathrm{Jones}\right)$ for $40 \mathrm{mWcm}^{-2}[39]$.

The external quantum efficiency (EQE) can be determined by the equation [41]; it provides the amount of conversion of the incident photons to electric current [42].

$$
E Q E=\frac{R h c}{e \lambda}
$$

where, $h$ is the Planck's constant, $c$ is the velocity of light and $\lambda$ is the wavelength of incident light. The calculated $E Q E$ values are listed in table 2 and the values increased gradually with increasing annealing temperature. The increasing trend of $E Q E$ is may be due to the increase in carrier mobility of the films. This might be due to the increase of responsivity revealed 
from the prepared $\mathrm{CdSe}$ based visible detector. However, the value of $E Q E$ is reasonably low than the previous reports [39]; due to its low film thickness and responsivity. Linear Dynamic Range (LDR) is also one of the key factors to realize the photodetector performance; and it can be calculated by the relation $L D R=20 \log \left(\frac{I_{\min }}{I_{\max }}\right)$ [43]. Here, $I_{\min }$ and $I_{\max }$ denotes the minimum in dark current and maximum in light current, respectively. The observed LDR of the prepared $\mathrm{CdS}$ : $\mathrm{Al}$ detector is $27 \mathrm{~dB}$, which is reasonably close to the reported $\mathrm{CdSe}$ detector $(37 \mathrm{~dB})$ [39]. The obtained minimum LDR value can represents the low ratio of photocurrent and dark current. We believe that the LDR value can be increased by increasing the ratio of current in both dark and light in future.

Mechanism of photodetector: In air condition, the mechanism of photodetector under dark and light can perform by the adsorption and desorption of oxygen and $\mathrm{H}_{2} \mathrm{O}$ on the film surface. Under dark condition, CdSe surface adsorbs the oxygen and $\mathrm{H}_{2} \mathrm{O}$ molecules from the atmospheric air which trap the electron from the conduction band; thereby creating a depletion layer with low conductivity near the CdSe film surface and further the earlier depletion layer is widened. Upon illumination condition, electron-hole pairs are generated as the photon energies above than the CdSe bandgap energy. This is because of the desorption of oxygen due to trapping of photo-generated holes as well as the direct photo-excitation of the captured electron from the conduction band (CB) [44]. The photon-generated holes transfer to the surface by the desorption of oxygen $\left[\mathrm{O}_{2}{ }^{-}+\mathrm{h}^{+}-\mathrm{O}_{2}(\mathrm{~g})\right]$ from the CdSe surfaces [45]. This process is continuing until the desorption of $\mathrm{O}_{2}$ reaches a stable state, as a result there is an increase of electron and holes until saturation during illumination. The desorption process can follow the above band/ and below band energy illuminations. Based on the observed CdSe band gap $(\sim 2.0 \mathrm{eV})$ which is opted for the above band energy illumination; accordingly, the electron and holes are directly generated in conduction band. The functions 
of both electron-hole pair generation and direct photo-excitations were gradually increased with respect to increase of different power intensity; resulting increase the photocurrent.
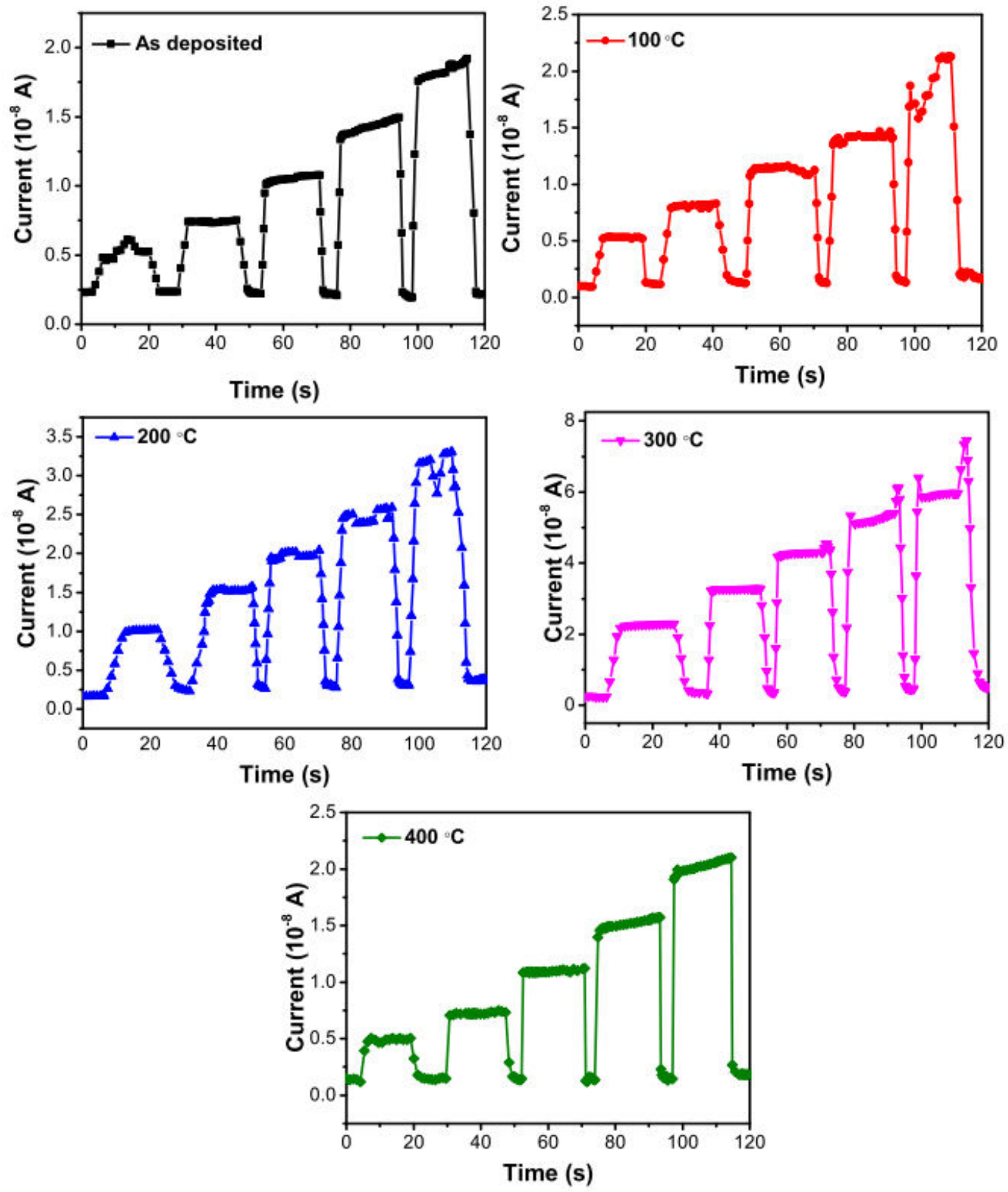

Figure 12. Plots of current $V s$. time of CdSe photodetector using different power intensity from $1 \mathrm{~mW} / \mathrm{cm}^{2}$ to $5 \mathrm{~mW} / \mathrm{cm}^{2}$

The transient photocurrent investigation is necessary to understand the photodetector performance of the prepared CdSe films. Time dependent photocurrent was performed with respect to different light intensities from 1 to $5 \mathrm{~mW} / \mathrm{cm}^{2}$ as given in Fig 12 . When the light 
interacts with the prepared film surface (ON light), the current level is quickly increased due to increase of the photo-generated charge carriers; while it decreased rapidly and reached to the base current when the light is turned OFF. Figure 12 revealed that the current level increases gradually with the increase of light intensity from $1 \mathrm{~mW} / \mathrm{cm}^{2}$ to $5 \mathrm{~mW} / \mathrm{cm}^{2}$. The photocurrent rise time and decay time can also be analyzed from the time dependent photocurrent measurement. The total time required to rise the photocurrent up to $90 \%$ from the base current called as rise time $\left(\tau_{\text {ris }}\right)$ whereas the total time taken to reach $10 \%$ of photocurrent from the maximum current is called as the decay time $\left(\tau_{\mathrm{dec}}\right)$. The obtained both rise and decay times for as-deposited and different annealed CdSe films are listed in table 2. In our case, both the rise time and decay time of $\mathrm{CdSe}\left(300^{\circ} \mathrm{C}\right)$ film is found to be $1 \mathrm{~s}$ and 2 s, respectively, which is quite faster than the previous report [46] for CdSe nanorods.

Table.2 Observed photo sensor parameters of the prepared CdSe thin film detectors.

\begin{tabular}{|c|c|c|c|c|c|}
\hline $\begin{array}{c}\text { CdSe } \\
\text { thin } \\
\text { films }\end{array}$ & $\begin{array}{c}\text { Responsivity } \\
\left(\mathbf{A W}^{-1}\right)\end{array}$ & $\begin{array}{c}\text { Detectivity } \\
\text { (Jones) }\end{array}$ & $\begin{array}{c}\text { External quantum } \\
\text { efficiency (EQE) } \\
(\boldsymbol{\%})\end{array}$ & $\begin{array}{c}\text { Rise } \\
\text { time }\end{array}$ & $\begin{array}{c}\text { Decay } \\
\text { time }\end{array}$ \\
\hline As-dep & 0.0033 & $3.88 \times 10^{9}$ & 0.77 & $1.2 \mathrm{~s}$ & $2.1 \mathrm{~s}$ \\
$100{ }^{\circ} \mathrm{C}$ & 0.0040 & $7.29 \times 10^{9}$ & 0.94 & $1.2 \mathrm{~s}$ & $2.1 \mathrm{~s}$ \\
$200{ }^{\circ} \mathrm{C}$ & 0.0053 & $7.45 \times 10^{9}$ & 1.25 & $1.1 \mathrm{~s}$ & $2 \mathrm{~s}$ \\
$300^{\circ} \mathrm{C}$ & 0.011 & $1.27 \times 10^{10}$ & 2.67 & $1 \mathrm{~s}$ & $2 \mathrm{~s}$ \\
$400^{\circ} \mathrm{C}$ & 0.0038 & $5.56 \times 10^{9}$ & 0.90 & $1 \mathrm{~s}$ & $2.2 \mathrm{~s}$ \\
\hline
\end{tabular}

\section{Conclusions}

CdSe thin films were successfully deposited on glass substrates by using thermal evaporation method. The XRD diffractograms indicated that the polycrystalline films are 
oriented along (002) and (103) plane. The SEM micrograph revealed the uniform distribution of the deposited films (free from cracks or pin-holes). EDS analysis showed that the CdSe thin films contain $\mathrm{Cd}$, and Se with appropriate quantities. The energy band gap was found to be increasing from $1.996 \mathrm{eV}$ to $2.093 \mathrm{eV}$ with annealing. Further, the films were analyzed for photodetector performance and the various parameters such photo responsivity (R), photo detectivity (D), external quantum efficiency (EQE) were calculated. The $300^{\circ} \mathrm{C}$ annealed CdSe film exhibited the highest photo-detectivity of $1.27 \times 10^{10}$ Jones. Importantly, it shows remarkably faster response time and decay time under the visible illumination. From the complete analysis, we believe that the prepared CdSe thin films can be used as an effective material for visible photodetector applications.

\section{Acknowledgements}

Authors would like to thank the Department of Physics, Centre for Nano Science and Engineering (CeNSE), IISc, Bengaluru, Karnataka, 560012 India for providing fabrication and characterization facilities. The author Ehab El Sayed Massoud would like to express his gratitude to the Deanship of Scientific Research at King Khalid University, Abha, Saudi Arabia, for funding part of this work through Research Groups Program under Grant No. R.G.P.2/70/42.

\section{References}

1 R. W. Robinson,Y. Han, H. Zhang, T. Ablekim, I. Khan, K. A. Persson, and A. Zakutayev, Wide Band Gap Chalcogenide Semiconductors, Chem. Rev. 120, 4007 (2020)

2 N. Mishra, V. G. Vasavi Dutt, and M. P. Arciniegas, Recent progress on metal chalcogenide semiconductor tetrapod-shaped colloidal nanocrystals and their applications in optoelectronics, Chem. Mater. 31, 9216 (2019)

3 D. Aldakov, A. Lefrançois and P. Reiss, Ternary and quaternary metal chalcogenide nanocrystals: synthesis, properties and applications, J. Mater. Chem. C. 1, 3756 (2013).

4 V. Saaminathan, K. R. Murali, Importance of pulse reversal effect of CdSe thin films for optoelectronic devices, J. Cryst. Growth. 279, 229 (2005) 
5 S. Mahato, A. K. Kar, Structural, Optical and electrical properties of electrodeposited cadmium selenide thin films for applications in photodetector and photoelectrochemical cell, J. Electroanalytical Chem.742, 23 (2015)

6 K. Sharma, A. S. Al-Kabbi, G. S.S. Saini, S.K. Tripathi, Thermally and optically induced effects on sub-band gap absorption in nanocrystalline $\mathrm{CdSe}$ (nc-CdSe) thin films, Curr. Appl Phys. 13, 964 (2013)

7 A. Yadav, M. A. Barote, E. U. Masumdar, Studies on cadmium selenide (CdSe) thin films deposited by spray pyrolysis, Mater. Chem. Phys. 121, 53 (2010)

8 H. M. Pathan, B. R. Sankapal, J. D. Desai, C. D. Lokhande, Preparation and characterization of nanocrystalline CdSe thin films deposited by SILAR method, Mater. Chem. Phys.78, 11 (2002)

9 P.C. González, G. R. Fragoso, J. G. Cruz, O. S. Salazar, Z. Angel, Synthesis of $\mathrm{CdSe}$ nanoparticles immersed in an organic matrix of amylopectin by means of $\mathrm{rf}$ sputtering, J. Cryst. Growth. 338, 251 (2012)

10 Y. Jiang, W. Zhang, J. Jie, X. Meng, X. Fan, S. Lee, Photo response properties of CdSe single-nanoribbon photodetectors, Adv. Funct. Mater. 17, 1795 (2007)

11 A. Singh, X. Li, V. Protasenko, G. Galantai, M. Kuno, H. G. Xing and D. Jena, Polarization-sensitive nanowire photodetectors based on solution-synthesized CdSe quantum-wire solids, Nano Lett. 7, 2999 (2007)

12 S. C. Kung, W. Xing, W. E. van der Veer, F. Yang, K. C. Donavan, M. Cheng, J. C. Hemminger and R. M. Penner, Tunable photoconduction sensitivity and bandwidth for lithographically patterned nanocrystalline cadmium selenide nanowires, ACS Nano. 5, 7627 (2011)

13 N. T. Shelke, S. C. Karle, B. R. Karche, Photo response properties of CdSe thin film photodetector, J. Mater. Sci: Mater. Elect. 31, 15061 (2020)

14 R. B. Kale, and C. D. Lokhande, Systematic Study on structural phase behavior of CdSe thin films, J. Phys. Chem. B. 109, 20288 (2005)

15 L. Xi, Yeng M. Lam , Y. P. Xu, L. J. Li, Synthesis and characterization of onedimensional $\mathrm{CdSe}$ by a novel reverse micelle assisted hydrothermal method, J. Colloid Inter. Sci. 320, 491 (2008)

16 T.S. Shyju, S. Anandhi, R. Indirajith, R. Gopalakrishnan, Solvothermal synthesis, deposition and characterization of cadmium selenide $(\mathrm{CdSe})$ thin films by thermal evaporation technique, J. Cryst. Growth. 337, 38 (2011)

17 I. H. Campbell and P. M. Fauchet, The effects of microcrystal size and shape on the one phonon Raman spectra of crystalline semiconductors, Solid State Commun. 58, 739 (1986)

18 V. M. Dzhagan, M. Ya. Valakh, A. E Raevskaya, A. L Stroyuk, S. Ya. Kuchmiy and D. R. T. Zahn, Resonant Raman scattering study of CdSe nanocrystals passivated with CdS and ZnS, Nanotechnology, 18, 285701 (2007)

19 R. Naik, A. Jain, R. Ganesan, K. S. Sangunni, Compositional dependence optical properties study of $\mathrm{As}_{40} \mathrm{Se}_{60-} \mathrm{Sb}_{\mathrm{x}}$ thin films, Thin Solid Films, 520, 2510 (2012)

20 J. Tauc, Amorphous and liquid semiconductors, Plenum Press, New York. 1974, p.171. 
21 R. Panda, R. Naik, N.C. Mishra, Thermal annealing induced evolution of $\mathrm{AgIn}_{5} \mathrm{Se}_{8}$ phase from Ag/ $\mathrm{In}_{2} \mathrm{Se}_{3}$ bilayer thin film, J. Alloys Comp. 778, 819 (2019)

22 E.A. Davis, N.F. Mott, Conduction in non-crystalline systems V. Conductivity, optical absorption and photoconductivity in amorphous semiconductors, Philos. Mag. 22, 903 (1970)

23 R. Swanepoel, Determination of the thickness and optical constants of amorphous silicon. J.Phys. E: Sci Instrum.16, 1214 (1983)

24 S. R. Elliott, The Physics and Chemistry of Solids, Wiley \& Sons Ltd, 2000

25 J. D. Yao, J. M. Shao, S. W. Li, D. H. Bao \& G. W. Yang, Polarization dependent photocurrent in the $\mathrm{Bi}_{2} \mathrm{Te}_{3}$ topological insulator film for multifunctional photodetection, Sci. Rep. 5, 14184 (2015)

26 S. H. Wemple, M. DiDomenico, Behavior of the Electronic Dielectric Constant in Covalent and Ionic Materials, Phy. Rev. B. 3, 1338 (1971)

27 M. M. El-Nahass, M. M. Sallam, M. A. Afifi, I. T. Zedan, Structural and optical properties of polycrystalline $\mathrm{CdSe}_{x} \operatorname{Te}_{1-x}(0 \leq x \leq 0.4)$ thin films, Mater. Res. Bull. 42, 371 (2007)

28 D. Sahoo, P. Priyadarshini, A. Aparimita, D. Alagarasan, R. Ganesan, S. Varadharajaperumal and R. Naik, Role of annealing temperature on optimizing the linear and nonlinear optical properties of $\mathrm{As}_{40} \mathrm{Se}_{50} \mathrm{Ge}_{10}$ films, RSC Adv. 10, 26675 (2020)

29 M. Behera, N. C. Mishra, R. Naik, C. Sripan, R. Ganesan, Thermal annealing induced structural, optical and electrical properties change in $\mathrm{As}_{40} \mathrm{Se}_{60-\mathrm{x}} \mathrm{Bi}_{\mathrm{x}}$ chalcogenide thin films, AIP Advances. 9, 095065 (2019)

30 M. M. El-Nahass, M.B. El-Den, H.M. El-Mallah, F.S. Abu-Samaha, Effect of Pb addition and heat treatment on optical properties of thermally evaporated $\mathrm{Ge}_{1-\mathrm{x}} \mathrm{Se}_{2} \mathrm{Pbx}$ thin films, J. Phys. Chem. Solids. 69, 2652 (2008)

31 E.R. Shaaban, M.Y. Hassaan, M.G. Moustafa, A. Qasem, G.A.M. Ali, E.S. Yousef, Optical constants, dispersion parameters and non-linearity of different thickness of $\mathrm{As}_{40} \mathrm{~S}_{45} \mathrm{Se}_{15}$ thin films for optoelectronic applications, Optik. 186, 275 (2019)

32 A. M. Abd-Elnaiem, R. M. Hassan, H. R. Alamri, H. S. Assaedi, Comparative investigation of linear and nonlinear optical properties of As-70 at\% Te thin films: influence of Ga content, J. Mater. Sci: Mater. Elect. 31, 13204 (2020)

33 S. Gao, X. Bao, Chalcogenide taper and its nonlinear effects and sensing applications, Science. 23, 100802 (2020)

34 H. Tichá, L. Tichy, Semiempirical relation between non-linear susceptibility (refractive index), linear refractive index and optical gap and its application to amorphous chalcogenides, J. Optoelect. Adv. Mater. 4, 381 (2002)

35 N.M. Ravindra, V.K. Srivastava, Electronic polarizability as a function of the penn gap in semiconductors. Infrared Phys. 20, 67 (1980)

36 M. Ravikumar, V. Ganesh, M. Shkir, R. Chandramohan, K. D. Arun Kumar, et al, Fabrication of $\mathrm{Eu}$ doped $\mathrm{CdO}[\mathrm{Al} / \mathrm{Eu}-\mathrm{nCdO} / \mathrm{p}-\mathrm{Si} / \mathrm{Al}]$ photodiodes by perfume atomizer based spray technique for optoelectronic applications, J. Mol. Struct. 1160, 311 (2018) 
37 I. Loyola Poul Raj, S. Valanarasu, K. Hariprasad, Joice Sophia Ponraj, N. Chidhambaram, V. Ganesh, H. Elhosiny Ali, Yasmin Khairy, Opt. Mater. 109, 110396 (2020)

38 Mohd. Shkir, I.M. Ashraf, S. AlFaify, Ahmed Mohamed El-Toni, Mukhtar Ahmed, Aslam Khan, A noticeable effect of Pr doping on key optoelectrical properties of CdS thin films, Ceramic Int. 46, 4652 (2020)

39 N. T.Shelke, D. J. Late, Hydrothermal growth of $\mathrm{MoSe}_{2}$ nanoflowers for photo- and humidity sensor applications, Sens. Actuators A:Phys. 295, 160 (2019)

40 M. Anitha, K. D. Arun Kumar, P. Mele, N. Anitha, K. Saravanakumar, M. A. Sayed, A. M. Ali and L. Amalraj, Synthesis and properties of p-Si/n-Cd1-xAgxO heterostructure for transparent photodiode devices, Coatings, 11, 425 (2021)

41 N. Reddy, Ch Venkata Reddy, M. Sreedhar, Migyung Cho, Effect of seed layers (Al, $\mathrm{Ti}$ ) on optical and morphology of Fe-doped $\mathrm{ZnO}$ thin film nanowires grown on $\mathrm{Si}$ substrate via electron beam evaporation, Mater. Sci. Semicond. Process. 71, 296 (2017)

42 W. Tian, H. Sun, L. Chen, P. Wangyang, X. Chen, J. Xiong, L. Li, Low-dimensional nanomateri al/Si heterostructure based photodetectors Info Mat. 1, 140 (2019)

43 K. D. Arun Kumar, P. Mele, M. Anitha, S. Varadharajaperumal, D. Alagarasan, N. S Alhokbany, T. Ahamad and S. M. Alshehri, Simplified chemical processed $\mathrm{Cd}_{1-\mathrm{x}} \mathrm{Al}_{\mathrm{x}} \mathrm{S}$ thin films for high-performance photodetector applications, J. Phys.: Condens. Matter. 33, 195901 (2021)

44 Li, Q. H., Gao, T., Wang, Y. G. \& Wang, T. H. Adsorption and desorption of oxygen probed from $\mathrm{ZnO}$ nanowire films by photocurrent measurements. Appl. Phys. Lett. 86, 1 (2005)

45 Q. An, X. Meng, K. Xiong and Y. Qiu, J. Mater. Chem. C, J. Mater. Chem. C. 5, 7057 (2017)

46 Y. Jiang, W. Zhang, J. Jie, X. Meng, X. Fan, S. Lee, Photo response properties of CdSe

single-nanoribbon photodetectors. Adv. Funct. Mater.17, 1795 (2007) 


\section{Supplementary figure}

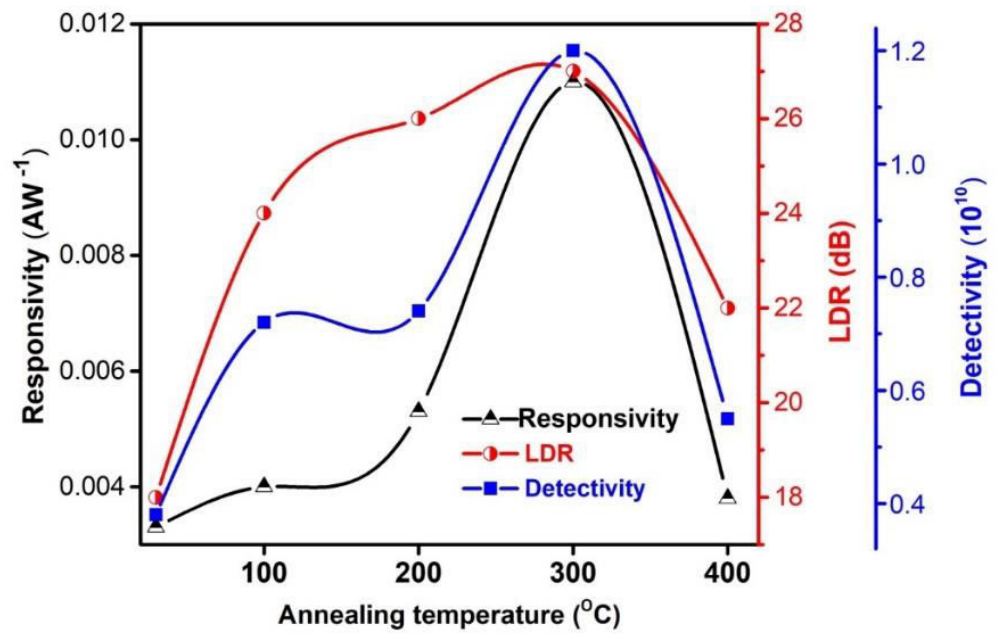

Fig. S1 Variations of responsivity $(R)$, linear dynamic range $(L D R)$ and detectivity $\left(D^{*}\right)$ with respect to different annealed CdSe films 


\section{Supplementary table}

Table -S1 Structural parameters of CdSe thin films with different annealing temperatures

\begin{tabular}{|c|c|c|c|c|}
\hline $\begin{array}{c}\text { Annealing } \\
\text { Temperature }(\mathbf{C})\end{array}$ & $\mathbf{2 \theta}(\mathbf{D e g})$ & $\mathbf{d}\left(\mathbf{A}^{\circ}\right)$ & $\mathbf{D}(\mathbf{n m})$ & hkl \\
\hline \multirow{2}{*}{$\mathrm{RT}$} & 25.49 & 0.31285 & 25.74 & 002 \\
\cline { 2 - 5 } & 45.91 & 0.60096 & 14.19 & 103 \\
\hline \multirow{2}{*}{$100^{\circ} \mathrm{C}$} & 25.48 & 0.29379 & 27.41 & 002 \\
\cline { 2 - 5 } & 45.92 & 0.64186 & 13.29 & 103 \\
\hline $200^{\circ} \mathrm{C}$ & 25.51 & 0.3325 & 24.22 & 002 \\
\cline { 2 - 5 } & 45.94 & 0.64004 & 13.33 & 103 \\
\hline $300^{\circ} \mathrm{C}$ & 25.48 & 0.28994 & 27.82 & 002 \\
\cline { 2 - 5 } & 45.93 & 0.682 & 12.51 & 103 \\
\hline $400^{\circ} \mathrm{C}$ & 25.474 & 0.2782 & 28.95 & 002 \\
\cline { 2 - 5 } & 45.91 & 0.63584 & 13.41 & 103 \\
\hline
\end{tabular}

RT-room temperature; D-crystallite size; 20-angle; d-inter-planar distance; hkl-miller indices 


\section{Declaration}

We certify that the manuscript, or any part of it, has not been published and will not be submitted elsewhere for publication while being considered by "Inorganic and Organometallic Polymers and Materials", There is no conflict of interest in the work. Thanking You.

Best regards,

R. Ganesan,

Principal Research Scientist,

Department of Physics,

Indian Institute of Science,

Bangalore-560012, Karnataka, India.

Mobile Number: 9148010945.

Mail Id: gans@iisc.ac.in 